\title{
Flood Risk Awareness Game (FRAG): Learning to Prepare in Flood Events
}

\author{
Chaiyaset Promsri \\ Rajamangala University of Technology Phra Nakhon, Bangkok, Thailand \\ Email: chaiyaset.p@rmutp.ac.th
}

Received: 24 October 2019; Revised: 26 November 2019; Accepted: 7 December 2019; Published: 19 December 2019

\begin{abstract}
This study aimed at developing flood awareness and preparedness board game. This game was the first flooding board game in Thailand. To design and develop this flooding board game, numerous steps in methodology were implemented. Firstly, the literature reviews of both research and board games were conducted. Analyzing and synthesizing these documents were carefully done to extract key elements of flood awareness and preparedness board game design and development. Secondly, brainstorming of experts in board game design and development and disasters fields were conducted to gain some ideas and integrated with concepts retrieved from the literature reviews. Thirdly, the first prototype of flood awareness and preparedness board game was launched and tested by the experts in a disaster filed. Next, game modification was done to adjust the game to be more attractive and effective based on experts' recommendations. Finally, the final version of this board game was prepared and launched for the test run with target groups across the country. This game consisted of 37 spaces including the victory point. Each space was assigned different special characters in which different characteristics of playing cards were applied and needed to be opened to make the flow and the enjoyment of the game. Players received knowledge based on the participation during the gameplay and the mechanics of this board game. To ensure that objectives of this board game development were met, pretest and protest were conducted as part of the gameplay.
\end{abstract}

Keywords: Floods, Flood awareness, Flood preparedness, Board games.

\section{Introduction}

In the past decade, severe flood incidents have increasingly become the major disaster of human being and significantly impacted ecosystems, properties, and infrastructure as well as human well-being (Kittipongvises and Mino, 2015). The major flood events of Thailand in 2011 caused huge devastations and losses for more than 10 million people in 65 provinces across the country (Promsri, 2017; Promsri, 2019). Numerous factors were perceived as key elements for huge damage in the historical flood incidents of Thailand such as mismanagement of the government, an increase of urbanization, and negative impacts of climate variability, the key factor of this disaster was resulted by the little knowledge and awareness of flood preparedness of Thai residents (Promsri, 2019).

Various attempts and efforts developed by many organizations to increase disaster awareness and preparedness of people in specific locations around the world (including floods), it seemed doubtful for the benefits individuals received from those methods (Edwards, 2014; Weichselgartner and Pigeon, 2015). In the lights of this, scholars attempted to find the other ways to help enhance individuals' awareness and preparedness, and a board game was considered as an effective tool to assist people in understanding and increasing their knowledge of floods. Treher (2001) argued that board games were not used for the entertainment purpose solely, but also an effective tool that helped develop skills and knowledge in a specific area remarkably.

Board games have been popularly utilized to foster disaster awareness and preparedness of people in the past years such as "Disaster Master" (UNESCO Asia and Pacific Regional Bureau for Education in Bangkok (Thailand), 2017), "The Disaster Awareness Game (DAG)" (Clerveaux, Spence and Katada, 
2008), and "Hazagora" (Mossoux et al., 2015). However, a board game that placed its emphasis on flood preparedness knowledge and awareness is scant and needs more attention on developing and designing to be used as an additional instrument of flood risk awareness improvement. Therefore, this present study aimed at designing and developing flood risk awareness board game for Thai citizens.

\section{Methodology}

Flood Risk Awareness Game was carefully designed and developed based on the following methodologies:

1) The researcher systematically reviewed numerous related literatures on disasters and floods concepts based on the information from The Thai Meteorological Department, The International Federation of Red Cross and Red Crescent Societies. (2015), American Red Cross (2016), Hyndman and Hyndman (2014), Koponnen (2009), Becker, Johnston, Coomer, and Ronan (2007), Didax (2007), Ministry of Civil Defense and Emergency Management (2007), and Drohan (2006).

2) The related literatures relating to board game design and development were carefully reviewed. Two basic concepts of Tinsman (2008) and Silverman (2013) were synthesized to use as principles for disasters-related board games and internationally famous board games analyses. Numerous well-known board games such as Millionaires, Snake and Ladders, Disaster, The Worst-Case Scenario Survival Game were incorporated for this study analysis to determine the key elements of board game design and development on flood awareness and preparedness. In addition, disaster-related board games such as "Disaster Master" (UNESCO Asia, 2007) "The Disaster Awareness Game: DAG" (Clerveaux, Spence and Katada, 2008) and "Hazagora" (Mossoux et al., 2015) were analyzed to identify the key concepts of disaster board game design and development. Documentary analysis and content analysis were major approaches in this step.

3) Once the second step was conducted, the brainstorming from 6 experts in a disasters field and game design and development were invited to the small brainstorming session to demonstrate their ideas and provide some opinions relating to flood awareness and preparedness board game design and development. Content analysis was done to retrieve main ideas of these experts.

4) After the first three steps were done, the researcher integrated all information retrieved from literature reviews and brainstorming to do the data analysis and determine principles of flood awareness and preparedness board game design and development.

5) Designed and developed the first prototype of flood awareness and preparedness board game.

6) Create the landscape and architecture of board game to be a proper size and attractive on the computer program.

7) Proposed the first prototype of this board game to 4 experts in disasters field to assess the overall of this board game in terms of mechanics, ideas, knowledge received after playing the game, duration, and amusement. The comments and recommendations of these experts were to use to adjust and modify this board game to be more attractive and knowledgeable for the targets.

8) After the game modification, this board game was experimented with a real play of the target group. Knowledge assessment and game satisfaction evaluation were conducted before and after playing this board game.

\section{Findings}

This study found the conclusions of flood awareness and preparedness board game design and development based on the integration of the first three steps of methodology as follows: 
1) This board game needed to set up the starting point and victory point. The starting point should be located in the different corner of the game, but the players would be jointed in the middle of the game.

2) The number of players for this board game should be limited to 4-6 people.

3) Duration for game play should not exceed an hour.

4) Paper bank notes (fake money) should be made as a supplementary of this board game to increase game fun.

5) The special spaces like opportunities and threats should be crated to increase game enjoyment. When a player fell into the special spaces, he/she was given a chance to open the card based on four different characteristics of the picture on the spaces including question cards (represented by rainy clouds picture), threat cards (represented by lightning clouds picture), flood kits card (represented by flooding house picture), and flood cards (represented by flooding picture).

6) Question cards should be created to measure knowledge of players on flood preparedness.

7) Flood kits should be made as a game card and players could use fake money to buy these tool kits when they determined it was necessary for their survival.

8) This board game contained 37 spaces from the starting point to the victory point.

After developing the first prototype, this board game was playtested by the experts in disasters field who spent approximately 30 minutes for playtesting. The recommendations from disasters experts were proposed as follows:

1) Questions and threat spaces should be created additional spaces as the first prototype had a few spaces for the opportunities and threats.

2) In case of a player who got only one more move to the victory point, a player needed to roll a dice an exact number of the number got left in order to be a winner.

3) The winner should be given a reward orderly such as the winner would get 1,000 THB (fake money), the first runner up would receive $500 \mathrm{THB}$, and the second runner up would earn 300 THB.

4) Reconsidered the probability of falling into the special spaces in order to gain knowledge of flood awareness and preparedness and have some enjoyment.

5) Determined the cost of assets held by each player to determine the winner. In addition, a player who lost a family member or members would miss the opportunity to win the game.

6) Created flood kits card with the picture of the kits and the designated price on each card.

7) Reviewed game rules once again to determine how to encourage players to read message on the threat cards first before talking about the punishment they received. Otherwise, players would not learn anything about flood awareness and preparedness.

8) Reassigned new criteria for punishment when players open flooding cards. In case of players opened the flooding card and did not have the tool kits with the same price or more expensive than the one existing on the card, players could save our move (instead of pausing their turn) by spending their money to buy that item with a higher price than regularity.

9) Pretest and posttest should be conducted to evaluate whether or not objectives of this board game were attained. Also, player satisfactions of this board game needed to be measured to use results as a guideline for developing a better board game in the future.

Overall, experts demonstrated their satisfaction on this board game design and development. They said that this board game was appropriate in terms of content and format for playing and provided knowledge of flood awareness and preparedness excellently. Moreover, the board game itself was created beautifully and attractively, which was proper for both youths and adults. As a consequence, the researcher took these experts' comments and recommendations into accounts and modified this flood awareness and preparedness board game, according to these recommendations. 
After receiving comments and recommendations from experts, game modification was conducted. Various additional parts and elements were added to make this board game to be more attractive and become a knowledgeable flood game. Additional aspects in the modification step of this game included:

1) Increased the numbers of special spaces. For example, the 12 questionnaire spaces were added and 5 threat spaces, 9 flood kits spaces, and 5 flooding spaces were supplemented.

2) Redesigned game rules for those who are to reach the victory point needed to roll the dice with an exact number for the space left to reach the final space.

3) Redesign game rules by providing bonuses for those who were the winner, the first runner up, and the second runner up.

4) The costs of assets were identified. For example, family members were priceless.

5) Recreated the flood kits cards to have pictures and prices.

6) Redesigned game rules to increase the knowledge of players during the game by allowing the player on the right hand side of a player who fell into the threat space read the information on the card to all players during the gameplay.

7) Knowledge assessment for pretest and protest of this board game was developed based on the related literature reviews on floods preparedness.

Figure 1 showed the final version of flood awareness and preparedness board game. Figure 2-5 displayed the different characteristics of cards used to play the board game after modification.

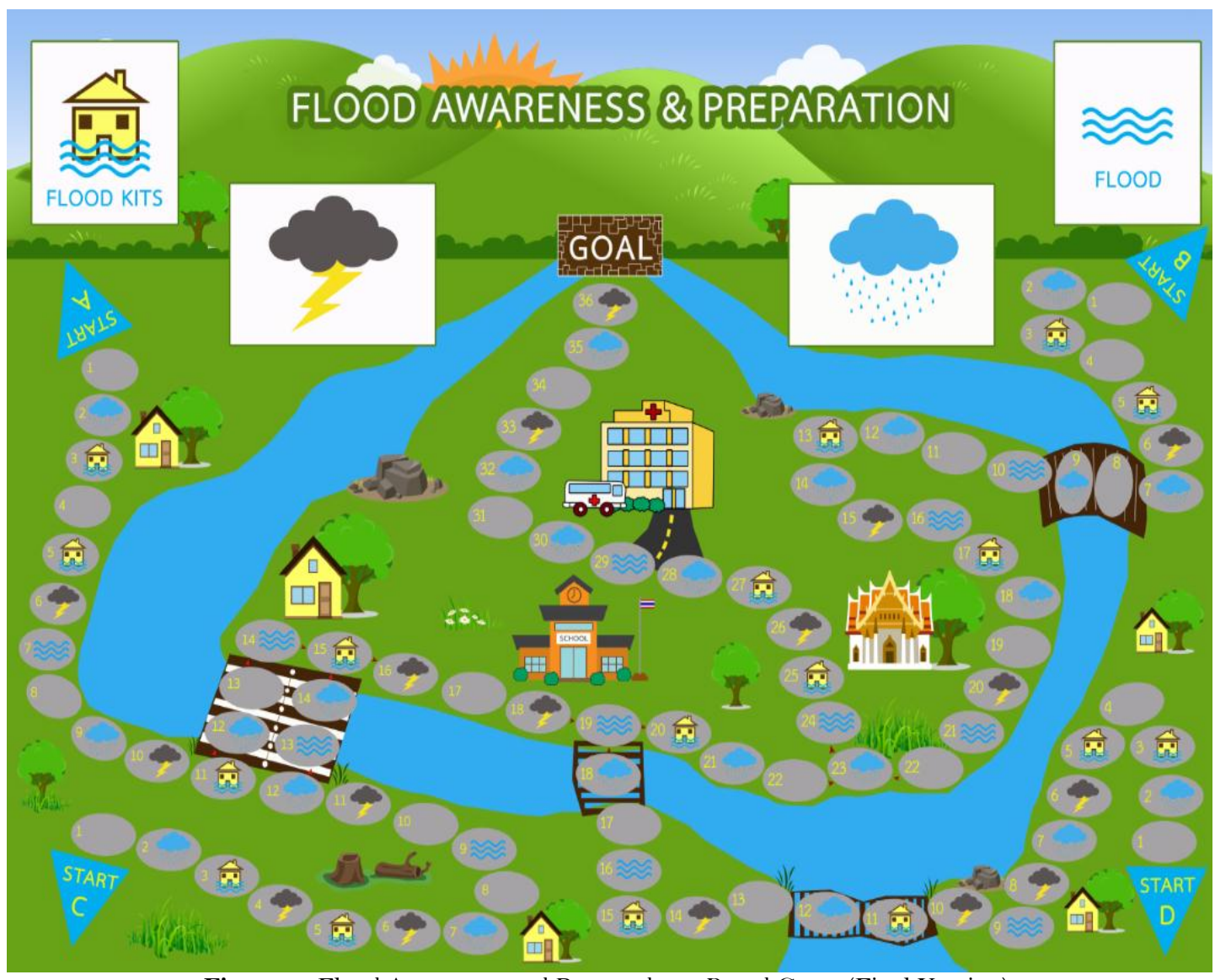

Figure-1. Flood Awareness and Preparedness Board Game (Final Version). 




Figure-2. Example of Threat Cards.

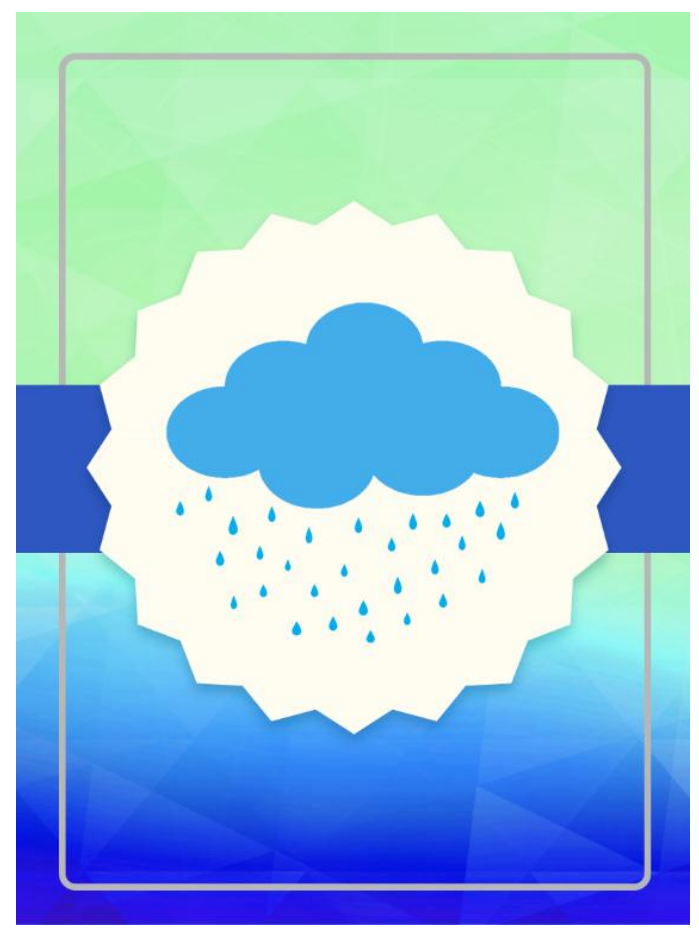

Figure-4. Example of Question Cards.

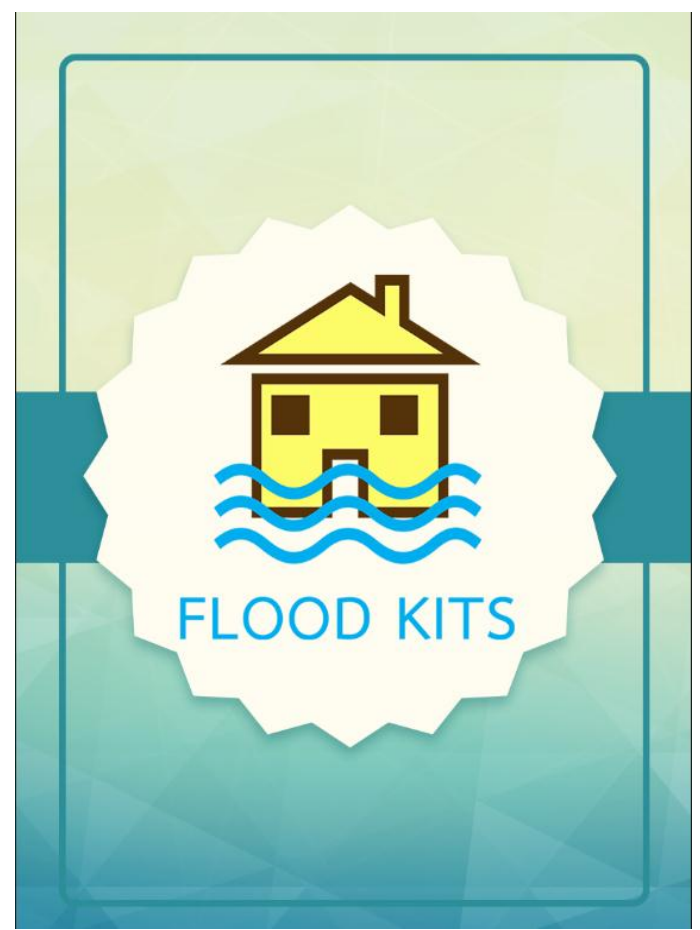

Figure-3. Example of Flood Kits Cards.

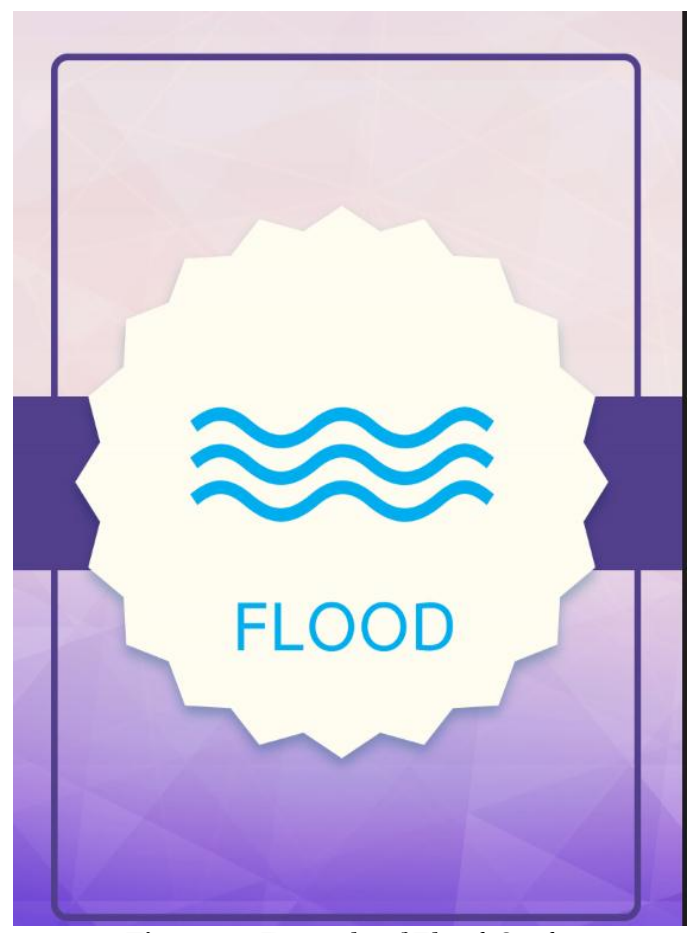

Figure-5. Example of Flood Cards.

\section{Conclusion, Discussions and Recommendations}

This study aimed at developing flood awareness and preparedness board game. This was the first flooding board game in Thailand. This game consisted of 37 spaces including the victory point. Each 
space was assigned different special character in which different characteristics of playing cards were applied and needed to be opened to make the flow and the enjoyment of the game. Players received knowledge based on the participation during the gameplay and the mechanics of this board game. To ensure the objectives of this board game development, pretest and protest were conducted as part of the gameplay. Since this board game was the first game relating to floods and disasters in Thailand, there might be some rooms for development available for this board game to become a more effective game in the future. Thus, test run the effectiveness and efficiency of this board game should be done through all ages of people in different locations and parts of Thailand. Also, player satisfactions measurement should be conducted to gain some ideas and comments from the real players for further development. This game should be utilized as part of lectures or trainings in disasters-related topic in all organizations to help prepare people to have better understanding and knowledge about flood preparation.

\section{Acknowledgement}

I am very thankful to Rajamangala University of Technology Phra Nakhon for research sponsorship and facility supports.

\section{References}

American Red Cross, (2016). Flood safety. Available from: https://www.redcross.org/get-help/how-to-preparefor-emergencies/types-of-emergencies/flood.html\#/About.

Becker, J., Johnston, D., Coomer, M. \& Ronan, K. (2007). Flood risk perceptions,education and warning in four communities in New South Wales, Australia - results of a questionnaire survey, November 2005, GNS Science Report 2007/30. pp: 66.

Clerveaux, V., Spence, B. \& Katada, T. (2008). Using game technique as a strategy in promoting disaster awareness in Caribbean multicultural societies: The disaster awareness game. Journal of Disaster Research, 3(5): 1-13.

Didax, (2007). Natural disaster (Grades 5-8). MA: World Teachers Press.

Drohan, M. I. (2006). Floods. NY: The Rosen Publishing Group, Inc.

Edwards, C. (2014). The federal emergency management agency: Floods, failures, and federalism. Cato Institute Policy Analysis, No. 764, November 2014. Available from: https://ssrn.com/abstract=2563413.

Hyndman, D. \& Hyndman, D. (2014). Natural hazards \& disaster. 4th Edn., Cengage Learning: International Edition.

Kittipongvises, S. \& Mino, T. (2015). Perception and communication of flood risk: Lessons learned about Thailand's flood crisis of 2011. Applied Environment Research, 37(1): 57-70.

Koponnen, L. (2009). Floods. NY: Weldon Owen Education, Inc.

Ministry of Civil Defense \& Emergency Management, (2007). Flood quiz - what'sthe plan stand? Available from: www.whattheplanstand.gov.nz/flood/flood-quiz/.

Mossoux, S., Delcamp, A., Poppe, S., Michellier, C, Canters, F. \& Kervyn, M. (2015).HAZAGORA: Will you survive the next disaster? - a serious game to raise awareness about geohazards and disaster risk reduction. Natural Hazard and Earth System Sciences, 3: 5209-5245.

Promsri, C. (2017). Exploring flood disaster preparedness awareness factors through historical flood victims in Bangkok metropolitan and vicinity by using factor analysis. International Journal of Research in Business and Social Sciences, 7(5): 1-7.

Promsri, C. (2019). Using google trends for investigating flood awareness of Thai citizens during 2011-2018. Cross-Currents: An International Peer-Reviewed Journal on Humanities \& Social Sciences, 5(5).

Silverman, D. (2013). How to learn board game design and development. Available from: http://gamedevelopment.tutsplus.com/articles/how-to-learn-board- gamedesign-and-development-gamedev-11607.

Tinsman, B. (2008). The game inventer's guidebook. Garden City, NY: Morgan James Publishing, LLC.

The International Federation of Red Cross and Red Crescent Societies, (2015). Preparing for flood. Available from: http://www.ifrc.org/en/what-we-do/disaster-management/preparing-fordisaster/.

Treher, E. N. (2011). Learning with board games. Available from: http://www.thelearningkey.com/pdf/Board Games TLKWhitePaper May16 201 1.pdf. 
UNESCO Asia and Pacific Regional Bureau for Education in Bangkok (Thailand), (2007). Disaster master: natural disaster preparedness

game. Available

from: http://unesco.org.pk/documents/ndm_Disaster_Master_Game.pdf.

Weichselgartner, J. \& Pigeon, P. (2015). The role of knowledge in disaster risk reduction. International Journal of Disaster Risk Science, 6(2): 107-116.

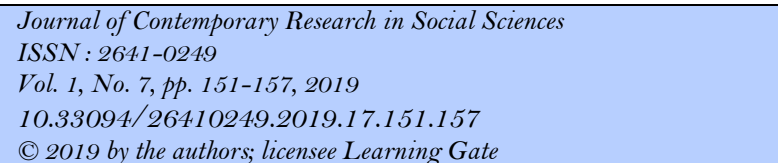

